\title{
Research on the Innovation of Scientific Research Organization Mode in Chinese Universities
}

\author{
Li-Na XUAN ${ }^{1, a}$ and Mao-Bing $\mathrm{HE}^{2, b,{ }^{*}}$ \\ ${ }^{1}$ Guangzhou College of Commerce, Guangzhou, China \\ ${ }^{2}$ South China Normal University, Guangzhou, China \\ axuanlina6@163.com, bhemby2006@qq.com \\ ${ }^{*}$ Corresponding author
}

Keywords: Colleges and Universities, Scientific Research Organization, Development.

\begin{abstract}
Since the concept of collaborative innovation was put forward, China's colleges and universities have continuously broken through internal and external mechanisms and barriers, vigorously promoted the deep integration of internal and external universities, and solved the problems of resource dispersion, redundant construction and low efficiency in the current innovation system. Therefore, it is of great significance to the sustainable development of colleges and universities to deeply analyze the development status of scientific research organization models in China, innovate scientific research organization mode, establish scientific and technological innovation coordination mechanism, and improve the use efficiency of scientific research resources.
\end{abstract}

\section{Introduction}

Innovation is the first driving force for the development of the country and the strategic support for the construction of China's economic system. The report of the 19th National Congress of the Communist Party of China put forward the goal of "establishing a technological innovation system, promoting synergy between industry, university and research, and accelerating the construction of an innovative country." The concept of "collaborative innovation" was once again proposed at the national strategic level. Collaborative innovation of colleges and universities under the background of "2011 Plan", with the core task of improving the innovation ability of talents, disciplines and scientific research, deepen the reform of the institutional mechanism of the university, and lead the collaborative innovation through the reform of the mechanism system. Leading the overall improvement of the innovation ability of colleges and universities with collaborative innovation. Since the implementation of the "2011 Plan" , universities have continuously broken through internal and external mechanisms and barriers, and have taken collaborative innovation centers as research carriers, vigorously promoted the deep integration of internal and external universities, and solved the problem of resource dispersion, redundant construction, and inefficiency in the current innovation system. problem. It should be said that the concept of "collaborative innovation" is not only a new organizational model for the national and regional society to improve the ability of independent innovation, but also a new scientific research paradigm for modern universities to meet the requirements of the development of the times. 


\section{The Status Quo of Scientific Research Organization Mode in Chinese University}

Scientific research ability is the core index to measure the comprehensive strength of a university. The rationality of the scientific research organization in colleges and universities, the efficiency and so on, all affect the quality of its scientific research activities.

\section{Vertical Scientific Research Organization Model}

For a long period of time, colleges and universities are mostly the vertical-scientific organization model of the "school-institution (department)-teaching and research section" from the bottom up, and the three-level management system is managed by the school and the principal is vertically led. This kind of scientific research organization is a typical teaching basic organization, and scientific research activities are attached to teaching activities. As a grassroots academic organization, the teaching and research section is not only responsible for implementing teaching activities, but also organizing scientific research activities. Its characteristics are based on the school-institution (department)-teaching and research room line management, the implementation of the school unified command, the functional department to assist in the form of guidance, the teaching and research section not only accepts the leadership and management of schools, colleges (departments), but also accepts the functional guidance of the functional departments And supervision. This kind of scientific research organization has a hierarchical nature, emphasizing that management information is transmitted from top to bottom along a fixed channel, and each member of the organization is at a certain level. Members are at different levels, and their responsibilities, work, and rights are different. The division of responsibilities of members is also clear; centralized and unified leadership makes decision-making and communication channels easier and faster, and reduces the burden on managers; The division of labor and management are more professional, the affiliation is clear, the powers and responsibilities are clear, and it helps to improve the efficiency of scientific research management.

However, there are many problems with this organizational model. First, power is too concentrated in the top management of the organization. The lack of necessary autonomy in grassroots organizations is not conducive to mobilizing the initiative and enthusiasm of the members of the organization, especially the scientific research personnel to participate in scientific research activities. Second, the division of disciplines within the organization is obvious, and too much attention is paid to the derivation and development of the same discipline, resulting in a narrow research field, a wide field of vision, and a wide range of issues, resulting in too clear boundaries between the disciplines and disciplines. Crossintegration has institutional obstacles, some scientific research resources are idle or lowutilization, and it is difficult to coordinate effectively. Third, organizational information transmission is slow and unresponsive, and it is not possible to change or adjust direction in time according to social needs, hindering the development of scientific and technological innovation. Fourth, there is a lack of effective communication and cooperation between different faculties and research centers. The flow of members is limited. The research activities are mostly self-issued, the research power is scattered, the research problems are single, the content is repeated, and it is difficult to concentrate the strengths to carry out crossdisciplinary research. Or undertake major scientific research projects, it is difficult to produce scientific research results with significant influence. In view of this, the vertical scientific research organization model of the linear function system has fundamental or structural defects. 


\section{Horizontal Scientific Research Organization Model}

With the increasing attention of scientific research in colleges and universities, scientific research teams have gradually become the main form of scientific research organizations in colleges and universities, and play an increasingly important role. The horizontal scientific research organization model came into being. Burton Clarke believes that the underlying structure of the higher education system is a discipline-based level that changes toward a differentiated and loose structure, and as the discipline and professional fields become more specialized, their form of aggregation becomes more and more loose, so it Follow the logic of disciplines, expertise, and specialized disorder[1].The specialization of knowledge has led to a more detailed discipline in the university, and the colleges, departments, and disciplines have all changed toward a differentiated and loose structure. This type of organization mode is based on the disciplines or first-level disciplines. The institute has research institutes, research (experimental) centers, etc., and implements school and hospital management. Its research activities are attached to teaching, and the members of the organization are completely divided according to their disciplines. Self-determination and academic atmosphere are easy, which is conducive to the relatively independent research of members of the organization, suitable for basic research work.

However, in the actual research work, it shows a loose, anarchic state. First, the colleges of most colleges still set up departments, and the departments or research institutes (research centers) are composed of multiple majors, or one major consists of multiple institutions (systems), with many functions, uncoordinated functions, and organizational structure. Loose, the school's school direction, school philosophy and teaching and research tasks cannot be widely understood and mastered by most teachers, teachers' research enthusiasm is significantly reduced. Second, because the teachers do not need to take classes after completing the teaching tasks, the working hours are relatively free and the mobility is large. The research activities within the organization are unorganized. Even if they participate in the research group, they are mostly individual behaviors, lacking among the members of the organization. Communication and communication. Third, due to the loose structure between the organizations, the scientific research materials, scientific research equipment, experimental rooms and other resources are not properly allocated, and it is easy to form contradictions and conflicts, resulting in the lack of some scientific research resources or being idle. The overall development of scientific research organizations.

\section{Interdisciplinary Scientific Research Organization Model}

The development of the era of knowledge economy has promoted the cooperation between different disciplines to become a new trend of scientific research activities. It is obviously out of date to rely on a certain discipline to solve complex problems, and interdisciplinary cooperation has become a necessity. In 2004, the Interdisciplinary Research published by the American Academy of Sciences defined interdisciplinary as: "Interdisciplinary research is the integration of information, materials, techniques, and knowledge from two or more disciplines (the field of expertise) through teams or individuals. Tools, perspectives, concepts, or theories to strengthen the fundamental understanding of issues that go beyond the boundaries of a single discipline or discipline, or to find solutions for them."[2]Interdisciplinary research requires the participation of people, finances, and things. Its most distinctive feature is its strong relevance. According to the characteristics of interdisciplinary research, interdisciplinary scientific research organizations are mainly 
project research, and the project team organizes relevant personnel to study project plans and determine the division of labor. On the other hand, the project team also needs to have managers to supervise the progress of the project and create conditions to make the research process more standardized and efficient, and to ensure the quality of the project. At the same time, the problems encountered by the project team in the research can also be fed back to the management staff in order to obtain more external support, such as government policies, financial support, and technical support of the enterprise. At the end of the project, the participants will reflect the research results into daily teaching activities, expand students' horizons and improve the quality of teaching. The structure of interdisciplinary research organization is shown in Figure 1[3]:

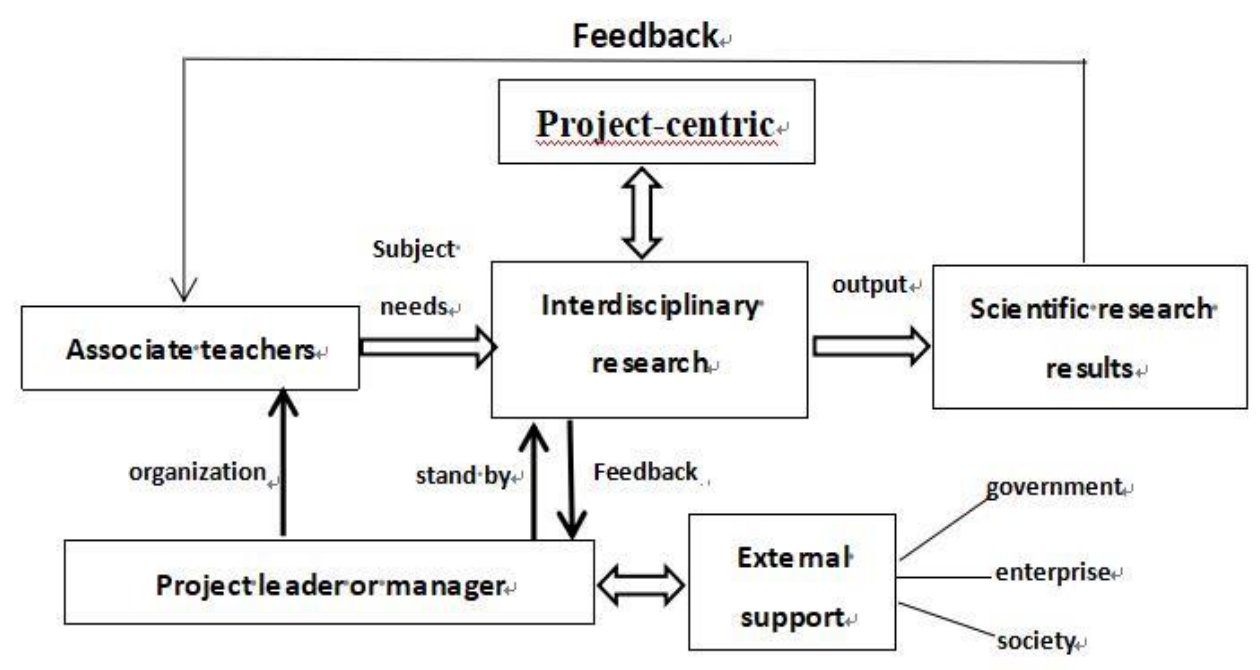

Figure 1. Interdisciplinary scientific research organization flow chart

However, interdisciplinary research organizations also have limitations. First, interdisciplinary scientific research organizations are established on the basis of the "schoolhospital-system"three-level management model. Most interdisciplinary scientific research organizations are affiliated with or attached to a college or department, and the daily operations of these organizations. The project application, funding allocation and other management work are also attributed to the college or department. The internal management system that is compatible with the interdisciplinary organization is not established in the organizational structure. It is still the traditional linear functional organization model. Therefore, it is impossible to concentrate on interdisciplinary advantages to apply for major issues, and it is difficult to play the enormous role that interdisciplinary scientific research organizations should have in scientific research. Second, even if the project is applied, the interdisciplinary scientific research organizations lack corresponding tracking management and effective supervision measures, which make many projects apply vigorously under the banner of "interdisciplinary research", but the project research work is slow and greatly reduced. The actual efficiency of interdisciplinary research organizations. Third, interdisciplinary scientific research organizations often adopt a matrix-like organizational structure. Although it is convenient for researchers from different colleges and disciplines to jointly tackle problems, at the same time, researchers must complete the research and teaching 
work of their affiliated colleges, and participate in the research. Interdisciplinary research activities have made them unable to concentrate on interdisciplinary research, leading to interdisciplinary cooperation in the form. Fourth, because interdisciplinary scientific research organizations cover a wide range of fields and involve a large number of participants, the organization's binding force is limited, which may easily lead to loose organization and chaotic management.

\section{Summary}

This Paper Introduce a competitive mechanism, establish an assessment and reward system, give diversified incentives in material and spiritual, and promote the scientific research strength of organizational members. Establish and improve the mechanism of diversified investment and multi-party cooperation, with research projects as the most basic scientific research activities, carry out joint research in various subject areas, and help regional local governments to solve important problems and key issues in economic construction. Outside the organization, the government should take the lead in formulating a policy system that is conducive to the deep integration of various innovation entities, providing funds to support scientific and technological innovation and transformation of results, creating an environment for social organization cooperation and scientific research culture, and building a support and participation system outside the research organization. Promote the optimal combination between the members of the organization, materials, institutions and spirits to achieve a dynamic balance. In scientific research organizations, administrative personnel are relatively fixed, they assume the role of some functional departments and still adopt the organizational model of linear functional system to provide guarantee and support for the operation of the entire scientific research organization. The horizontal scientific research organization is based on scientific research projects. Members can come from different innovation subjects, break the original institutional barriers, and focus on research tasks to build an organizational model based on matrix structure. With the research process of scientific research projects, the research team is continuously organized, developed, deconstructed and reorganized to promote knowledge exchange, continuously stimulate the scientific and technological innovation ability of each innovation subject, and promote the self-renewal of universities and other innovative subjects to form a new and efficient Collaborative innovation research organization model.

\section{Acknowledgement}

This research was financially supported by the special fund project of disciplines and professional construction in higher education institutions in Guangdong Province. "Research on the innovation of scientific research organization model in the perspective of collaborative innovation--taking Guangdong Province as an example" (No.2013WYXM0169), Guangdong Higher Education Teaching Research and Reform Project "Research on the Reform of Teaching and Research Organizations in Applied Undergraduate Universities - Based on the Perspective of Innovative Talent Cultivation (No. 2018XJJXGG02), Guangdong Province Education Science "Twelfth Five-Year Plan" Project "Colleges of Higher Education, Economics and Research, "Five Rings Drive" Collaborative Education Research on Innovation Models and Mechanisms (No. 2013JK334), Education Research Project of Guangdong Education Research Institute "Study on Collaborative Innovation System 
Mechanism of Higher Education - Based on the Perspective of Institutional Innovation" (No. GDJY-2014-C-b015).

\section{References}

[1] Burton Clark, Higher Education System--A Transnational Study of Academic Organizations, Hangzhou University Press, HangZhou, 1994.

[2] Promote interdisciplinary research reports, American Academy of Sciences Press, 2004.

[3] Fu-tao TANG, Yu-ping FENG, Chun-yang LI, Chen MA, Study on Interdisciplinary Scientific Research Organization Model in Colleges and Universities, Contemporary Education Theory and Practice, (2014)40-42. 